\title{
Role of biodegradable stents in octogenarians with achalasia
}

\section{다 (용}

\author{
Authors \\ Rami El Abiad', Mouen A. Khashab² \\ Institutions \\ 1 Division of Gastroenterology and Hepatology, University \\ of lowa, lowa City, lowa, United States \\ 2 Division of Gastroenterology and Hepatology, Johns \\ Hopkins Hospital, Baltimore, Maryland, United States
}

Bibliography

Endosc Int Open 2021; 09: E767-E769

DOI 10.1055/a-1393-5665

ISSN 2364-3722

(c) 2021. The Author(s).

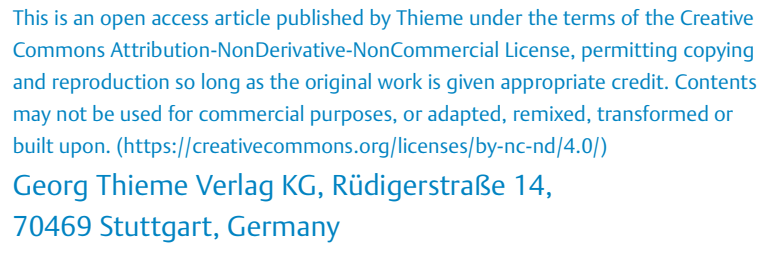

This is an open access article published by Thieme under the terms of the Creative Commons Attribution-NonDerivative-NonCommercial License, permitting copying and reproduction so long as the original work is given appropriate credit. Contents may not be used for commercial purposes, or adapted, remixed, transformed or built upon. (https://creativecommons.org/licenses/by-nc-nd/4.0/)

Georg Thieme Verlag KG, Rüdigerstraße 14, 70469 Stuttgart, Germany

Corresponding author Rami El Abiad, MD, University of lowa Hospitals and Clinics, 4612 JCP, lowa City, IA 52241, United States

Fax: +1-443-683-8335

rami-elabiad@uiowa.edu
Achalasia is a primary motility disorder of the esophagus characterized by the loss of inhibitory neurons in the myenteric plexus. Incidence peaks in the third and seventh decades of life $[1,2]$ It is an incurable disease and definitive treatment is aimed at disrupting the lower esophageal sphincter (LES). Aggressive treatment routes tend to be more durable but are fraught with potentially morbid adverse events (AEs) that may not be tolerated by those with little health reserve. Pneumatic dilation (PD) and laparoscopic Heller myotomy (LHM) have historically been the mainstay therapeutic interventions in patients with acceptable surgical risks. Per-oral endoscopic myotomy (POEM) has emerged as a non-inferior alternative to LHM with comparable risk profile. It is known that higher American Society of Anesthesiologists (ASA) score is associated with more anesthesia-related serious AEs [3]. Due to fear of procedure-related AEs in the face of increased burden of medical comorbidities, achalasia patients 75 years and older are sometimes left untreated [4]. Medication use, akin to nitrates and calcium channel blockers, is virtually ineffective and is marred by intolerable cardiovascular AEs. Botulinum toxin injection is a viable choice, albeit with limited effectiveness and durability [4].

While the early use of self-expandable metal stents (SEMS) in achalasia failed to provide sustained symptom relief and was associated with high morbidity, other publications have shown that SEMS can be successfully and safely employed for the same purpose $[5,6]$. These publications, however, seem to originate from the same investigating group, which calls into question whether there is an overlap in the patient cohort that has been reported at different times [7-9]. Regardless, Li et al. published their study about long-term follow-up for patients with achalasia treated with either pneumatic dilation $(\leq 32 \mathrm{~mm})$ or covered SEMS of varying diameters $(20 \mathrm{~mm}, 25 \mathrm{~mm}$ and $30 \mathrm{~mm}$ ). Although the stent was kept in-situ no longer than a week, $83 \%$ of patients treated with 30-mm SEMS had clinical remission for a mean follow-up of 7 years [10].

The first reported case of biodegradable stent (BDS) use for achalasia emerged around the same time but was complicated with stenosis related to hyperplastic tissue development [11]. Hernandez Mondragon et el. in this prospective study titled "Safety and efficacy of biodegradable stents in octogenarian patients with esophageal achalasia" report their experience with BDS use in a cohort of octogenarian patients with achalasia who were too sick for, or opted against more invasive therapy [12]. Thirty-two patients with a median age of 82 years were included in this single-center study with only 18 patients completing the 9-year follow-up. A control group was lacking. Achalasia was diagnosed using high-resolution esophageal manometry (HREM) according to Chicago classification. Endoscopy and computed tomography were used to rule out pseudoachalasia and serology to rule out Chaga's disease. A $25 \mathrm{~mm} \times$ $60 \mathrm{~mm}$ BDS was placed across and was centered $1 \mathrm{~cm}$ above the esophagogastric junction. Early stent migration occurred in six patients (18\%) by 1 month and was addressed with repeat stenting. At 6 months, 18 patients (56\%) presented with dysphagia, five of whom (16\%) were found to have stenotic tissue hyperplasia. All these patients responded to CRE balloon dilation to $15 \mathrm{~mm}$. Clinical success was achieved when all the following criteria were met after 6-month follow-up: Eckardt score $(\mathrm{ES})<3$, timed barium esophagram $\geq 80 \%$ at $5 \mathrm{~min}$, and 
integrated relaxation pressure (IRP) $<15 \mathrm{~mm} \mathrm{Hg}$. Patients with partial response (PR) were those with $E S \geq 3$, and IRP $\geq 15 \mathrm{~mm}$ $\mathrm{Hg}$ or $\mathrm{TBE}<50 \%$. If patients were found to have $\mathrm{PR}$ after two consecutive follow-ups, they were considered as failures. Although balloon size was not reported, all failures were salvaged with pneumo-dilation with no AEs. At the conclusion of the study, there were eight failures and six deaths. After 9 years, clinical success rates of $94 \%, 72 \%$, and $65 \%$ were reported for time point evaluation, per protocol, and intention-to-treat analysis, respectively.

Biodegradable stents have historically been used for cardiovascular indications. There is only one available esophageal BDS in clinical use: the SX-ELLA (ELLA-CS, s.r.o. Hradec Kralove, Czech Republic). Of the different biodegradable polymers, the SX-ELLA is made of polydioxanone (PDS)- the same semicrystalline polymer of resorbable surgical sutures. PDS polymers degrade via hydrolysis into carbon dioxide and water - a process that can be affected by several variables and accelerated by low $\mathrm{pH}$ - thus the need for acid inhibitors [13]. SX-ELLA is a self-expanding loadable stent (SES) which maintains its integrity and radial force for 6 to 8 weeks, after which the mesh starts to degrade before completely disintegrating in 11 to 12 weeks post implantation. Although available in different lengths (60 $\mathrm{mm}$ to $135 \mathrm{~mm}$ ), the widest available diameter is $25 \mathrm{~mm}$ for the body and $31 \mathrm{~mm}$ for the flares. The advantage of BDS is that it does not require endoscopic retrieval even if it migrates. BDS use can be associated with certain limitations and potential risks. As a foreign body, and being uncovered, the BDS is prone to reactive tissue ingrowth and overgrowth. Although this phenomenon can help anchor the stent and prevent migration, the secondary stenosis is a common cause of dysphagia and requires endoscopic intervention. Still, and as with other stents, the BDS is prone to early migration necessitating repeat stent placement. Stent degradation can dampen radial expansile strength rendering it ineffective and obliging the patient and treating physicians to reconsider invasive interventions previously circumvented. The prolonged effect post BDS disintegration is unclear but is possibly due to sustained and symmetric muscle rupture with associated tissue remodeling.

It has been debated as whether achalasia in the elderly is a "different disorder" compared to the young when it comes to presentation, experience and outcome. [14] Elderly patients with achalasia tend to have lower sphincter pressures and seem to be less symptomatic [15]. Irrespective of phenotype, and independent of age, myotomy (LHM or POEM) is relatively safe and is proven to provide prolonged symptomatic relief [14, $16,17]$. In a multicenter study, Chen et. al demonstrated that POEM carries $93.4 \%$ technical success and $90.8 \%$ clinical success in 76 octogenarians with achalasia with $14.5 \% \mathrm{AE}$ rate, all mild to moderate in severity [4]. Octogenarians, compared to younger peers, experience higher incidence of perioperative AEs $[4,18]$. Thus, in an aging population, exploring supplementary treatment options seems logical- if not necessary [19]. The current study postulates that BDS placement offers an efficient, relatively safe alternative that affords acceptable symptomatic improvement with durability in patients with compromised longevity due to age or illness. The study was limited by the small sample size and the lack of control or comparison group; which the authors dutifully acknowledge. ASA scores were not included, which compromised the ability to gauge how sick the patients were and whether proceeding with BDS was more of a cautious decision by the patient or the treating physician, especially that all "failures" underwent PD with no AEs. A question that lingers after reading this study and the earlier studies with SEMS use for achalasia is how can a stent being present for 2 months (or less than a week for the case of SEMS) provide sustained relief for almost a decade? This article certainly rekindles past interest in the use of SEMS for a benign esophageal disease but does it offer a paradigm shift in the treatment of achalasia in the frail and the elderly? Not quite yet.

\section{Competing interests}

Dr. Khashab is a consultant for BSCl, Olympus, Medtronic, and GI Supply.

References

[1] Mayberry JF. Epidemiology and demographics of achalasia. Gastrointest Endosc Clin N Am 2001; 11: 235-248

[2] Park W, Vaezi MF. Etiology and pathogenesis of achalasia: the current understanding. Am J Gastroenterol 2005; 100: 1404-1414

[3] Early DS, Lightdale JR. ASGE Standards of Practice Committee. et al. Guidelines for sedation and anesthesia in $\mathrm{Gl}$ endoscopy. Gastrointest Endosc 2018; 87: 327-337

[4] Chen YI, Inoue H, Ujiki M et al. An international multicenter study evaluating the clinical efficacy and safety of per-oral endoscopic myotomy in octogenarians. Gastrointest Endosc 2018; 87: 956-961

[5] Mukherjee S, Kaplan DS, Parasher G et al. Expandable metal stents in achalasia-is there a role? Am J Gastroenterol 2000; 95: 2185-2188

[6] Cheng YS et al. Selection and evaluation of three interventional procedures for achalasia based on long-term follow-up. World J Gastroenterol 2003; 9: 2370-2373

[7] Cheng YS, Li M-H, Chen W-X et al. Temporary self-expanding metallic stents for achalasia: a prospective study with a long-term follow-up. World J Gastroenterol 2010; 16: 5111-5117

[8] Li YD, Chen Y-S, Li M-H et al. Temporary self-expanding metallic stents and pneumatic dilation for the treatment of achalasia: a prospective study with a long-term follow-up. Dis Esophagus 2010; 23: 361-367

[9] Zhu Y-Q, Cheng Y-S, Tang G-Y et al. Comparison of temporary stent insertion with pneumatic dilation of the same diameter in the treatment of achalasia patients: a retrospective study. J Gastroenterol Hepatol 2010; 25: 499-505

[10] Li YD, Tang G-Y, Cheng Y-S et al. 13-year follow-up of a prospective comparison of the long-term clinical efficacy of temporary self-expanding metallic stents and pneumatic dilatation for the treatment of achalasia in 120 patients. AJR Am J Roentgenol 2010; 195: 14291437

[11] Hair CS, Devonshire DA. Severe hyperplastic tissue stenosis of a novel biodegradable esophageal stent and subsequent successful management with high-pressure balloon dilation. Endoscopy 2010; 42: E132E133

[12] Hernandez-Mondragon OGC, Pineda L, Michel O. Safety and efficacy of biodegradable stents in octagenarian patients with esophageal achalasia. Endosc Int Open 2021; 09: E756-E766 
[13] Hollinger JO, Battistone GC. Biodegradable bone repair materials. Synthetic polymers and ceramics. Clin Orthop Relat Res 1986; 207 : 290-305

[14] Downs DJ, Jadick G, Swaid F et al. Age and achalasia: how does age affect patient presentation, hospital course, and surgical outcomes? Am Surg 2017; 83: 952-961

[15] Schechter RB, Lemme EMO, Novais P et al. Achalasia in the elderly patient: a comparative study. Arq Gastroenterol 2011; 48: 19-23

[16] Sanaka MR, Chadalavada P, Alomari M et al. Peroral endoscopic myotomy is a safe and effective treatment modality for geriatric patients with achalasia. Esophagus 2020; 17: 484-491
[17] Craft RO, Aguilar BE, Flahive $C$ et al. Outcomes of minimally invasive myotomy for the treatment of achalasia in the elderly. JSLS 2010; 14 : 342-347

[18] Abe H, Tanaka S, Kawara F et al. Comparison of the safety and efficacy of peroral endoscopic myotomy between octogenarians and non-octogenarians. Dig Endosc 2021; 33: 110-117

[19] Lutz W, Sanderson W, Scherbov S. The coming acceleration of global population ageing. Nature 2008; 451: 716-719 